\title{
Bone microarchitecture in ankylosing spondylitis and the association with bone mineral density, fractures, and syndesmophytes
}

Eva Klingberg ${ }^{1 *}$, Mattias Lorentzon ${ }^{2}$, Jan Göthlin ${ }^{3}$, Dan Mellström², Mats Geijer ${ }^{4}$, Claes Ohlsson², Elizabeth J Atkinson ${ }^{5}$, Sundeep Khosla ${ }^{6}$, Hans Carlsten $^{1}$ and Helena Forsblad-d'Elia ${ }^{1}$

\begin{abstract}
Introduction: Osteoporosis of the axial skeleton is a known complication of ankylosing spondylitis (AS), but bone loss affecting the peripheral skeleton is less studied. This study on volumetric bone mineral density (vBMD) and bone microarchitecture in AS was conducted to compare peripheral VBMD in AS patients with that in healthy controls, to study VBMD in axial compared with peripheral bone, and to explore the relation between vertebral fractures, spinal osteoproliferation, and peripheral bone microarchitecture and density.
\end{abstract}

Methods: High-resolution peripheral quantitative computed tomography (HRpQCT) of ultradistal radius and tibia and QCT and dual-energy $x$-ray absorptiometry (DXA) of lumbar spine were performed in 69 male AS patients (NY criteria). Spinal radiographs were assessed for vertebral fractures and syndesmophyte formation (mSASSS). The HRPQCT measurements were compared with the measurements of healthy controls.

Results: The AS patients had lower cortical VBMD in radius $(P=0.004)$ and lower trabecular VBMD in tibia $(P=0.033)$, than did the controls. Strong correlations were found between trabecular $\vee B M D$ in lumbar spine, radius $\left(r_{S}=0.762 ; P<0.001\right)$, and tibia $\left(r_{S}=0.712 ; P<0.001\right)$.

When compared with age-matched AS controls, patients with vertebral fractures had lower lumbar cortical VBMD $(-22 \% ; P=0.019)$, lower cortical cross-sectional area in radius $(-28.3 \% ; P=0.001)$ and tibia $(-24.0 \% ; P=0.013)$, and thinner cortical bone in radius $(-28.3 \% ; P=0.001)$ and tibia $(-26.9 \% ; P=0.016)$.

mSASSS correlated negatively with trabecular VBMD in lumbar spine $\left(r_{S}=-0.620 ; P<0.001\right)$, radius $\left(r_{S}=-0.400\right.$; $p=0.001)$ and tibia $\left(r_{S}=-0.475 ; p<0.001\right)$ and also with trabecular thickness in radius $\left(r_{S}=-0.528 ; P<0.001\right)$ and tibia $\left(r_{S}=-0.488 ; P<0.001\right)$.

Adjusted for age, syndesmophytes were significantly associated with decreasing trabecular VBMD, but increasing cortical $\vee B M D$ in lumbar spine, but not with increasing cortical thickness or density in peripheral bone. Estimated lumbar vBMD by DXA correlated with trabecular vBMD measured by QCT $\left(r_{S}=0.636 ; P<0.001\right)$.

Conclusions: Lumbar osteoporosis, syndesmophytes, and vertebral fractures were associated with both lower VBMD and deteriorated microarchitecture in peripheral bone. The results indicate that trabecular bone loss is general, whereas osteoproliferation is local in AS.

\footnotetext{
* Correspondence: Eva.Klingberg@vgregion.se

${ }^{1}$ Department of Rheumatology and Inflammation Research, Sahlgrenska

Academy at the University of Gothenburg, Gothenburg, Sweden

Full list of author information is available at the end of the article
} 


\section{Introduction}

Ankylosing spondylitis (AS) is a chronic inflammatory rheumatic disease predominantly affecting the sacroiliac joints and the vertebral column. The disease often leads to the formation of spinal syndesmophytes and impaired back mobility, especially in male patients. Patients with AS have, in comparison with the general population, an increased risk of developing osteoporosis and fractures, especially vertebral fractures, but also other fractures, including hip fractures [1-6]. Male sex, old age, long disease duration, elevated inflammatory parameters, advanced chronic AS-related changes in the spine, and poor back mobility have been identified as risk factors for osteoporosis and vertebral fractures [7-13]. The mechanisms behind inflammation, new-bone formation and osteoporosis in AS are incompletely understood.

Measurements of lumbar area bone mineral density $(\mathrm{aBMD})$ with dual-energy $\mathrm{x}$-ray absorptiometry (DXA) in the anteroposterior (AP) projection are unreliable in AS, because of the spinal osteoproliferation [13-15]. Furthermore, prospective studies of the general population have shown that aBMD identifies only $20 \%$ of men who will later sustain a fracture [16,17]. Bone strength depends partly on bone mineral content, but also on the bone geometry and microarchitecture of cortical and trabecular bone [18-20]. Quantitative computed tomography (QCT) has the advantage of assessing volumetric BMD (vBMD) in the lumbar spine in cortical and trabecular bone separately, without including areas of hyperostosis in the measurements [15].

The development of high-resolution peripheral quantitative computed tomography (HRpQCT) has enabled us to study bone in great detail, without the need of biopsies. Although several studies exist on osteoporosis in AS, the knowledge of the bone microarchitecture in the disease is still sparse. The evolving technique of HRpQCT offers new possibilities to study further the intricate association between new bone formation and osteoporosis in AS and also to follow up the effects of treatment for osteoporosis and inflammation on bone tissue. This is, to our best knowledge, the first study on bone microarchitecture in AS with HRpQCT.

The aims of the present study were to (a) study peripheral vBMD in AS patients in comparison with healthy controls, (b) compare vBMD of trabecular and cortical bone in the axial and peripheral skeleton, (c) explore the relation between bone microarchitecture and presence of vertebral fractures and syndesmophytes, and (d) compare lumbar BMD measured with QCT and DXA in the AP and lateral projections.

\section{Methods}

\section{Patients}

In total, 69 male AS patients who had been included in a larger study on osteoporosis in the west of Sweden were randomized in an age-adjusted algorithm also to take part in the current study on HRpQCT and QCT. All AS patients registered at the Rheumatology Clinic at Sahlgrenska University Hospital in Gothenburg, and the Rheumatology Clinics at Borås and Alingsås county hospitals had been invited to take part in the initial study. The inclusion of the 204 patients in the initial study has been described in detail [13]. In summary, all included patients met the modified New York criteria for AS [21] .Exclusion criteria were psoriasis, inflammatory bowel disease, dementia, and difficulties in understanding Swedish. Written informed consent was obtained from all patients. The study was approved by the Regional Ethical Review Board in Gothenburg and carried out in accordance with the Helsinki declaration.

\section{Healthy controls}

The HRpQCT results regarding trabecular and cortical vBMD of the AS patients were compared with the results of a control group consisting of 68 healthy individuals measured with the same type of XtremeCT at the Mayo Clinic in Rochester, Olmsted County, Minnesota, USA. The healthy controls were matched for age, height, weight, and race. No control could be found for the youngest patient, who thus was excluded from these calculations.

\section{High-resolution peripheral quantitative computed tomography}

Bone microarchitecture was examined by using an HRpQCT device (XtremeCT; Scanco Medical AG, Brüttisellen, Switzerland) in the nondominant ultradistal radius and tibia. The patient's forearm and leg were immobilized in especially designed carbon-fiber shells (Scanco Medical) to prevent movement during the procedure.

The quality of the measurements was assessed by using a 5 -point scale recommended by the manufacturer (1, excellent; 2, good; 3 , acceptable; 4, unacceptable; 5 , poor). Only examinations with quality grades 1 through 3 were included in the study, whereas grades 4and 5 were excluded, mostly because of motion artefacts. Totally 12 examinations of the radius had to be repeated because of to movement artifacts. Seven patients had measurements of the ultradistal radius with unacceptable quality and were thus excluded, whereas all tibia measurements were included.

The volumes of interest (VOIs), 9-mm sections of radius and tibia, were examined in 110 parallel slices (voxel size, $82 \mu \mathrm{m})$, generating a 3D representation of the bone. The first CT slices started $9.5 \mathrm{~mm}$ and $22.5 \mathrm{~mm}$ proximal to a reference line manually placed at the center of the end plate of the distal radius and tibia, respectively, and continued proximally.

The VOIs were automatically separated into a trabecular and a cortical region. With previously described data- 
extracting procedures, the following parameters for the trabecular and cortical bone were obtained: trabecular volumetric BMD (DTrab; $\mathrm{mg} / \mathrm{cm}^{3}$ ), trabecular bone volume/total volume (BV/TV; \%), trabecular number (TbN; per $\mathrm{mm})$, trabecular thickness $(\mathrm{TbTh} ; \mu \mathrm{m})$, trabecular separation or spacing $(\mathrm{TbSp} ; \mu \mathrm{m})$, cortical volumetric BMD (DCort; $\mathrm{mg} / \mathrm{cm}^{3}$ ), cortical bone cross-sectional area $\left(\right.$ CortCSA; $\left.\mathrm{mm}^{2}\right)$, cortical periosteal circumference (CortPm; mm), and cortical thickness (CortTh; $\mu \mathrm{m}$ ) [22-26]. DTrab, DCort, TbN, CortCSA, and CortPm were measured directly, and the other parameters were derived.

The coefficients of variation (CVs) for repeated measurements by using the XtremeCT apparatus in Gothenburg ranged between $0.3 \%$ and $3.9 \%$ of the radius and from $0.1 \%$ to $1.6 \%$ of the tibia. The same device, software, and operator were used throughout the study.

The software Autocontouring and Eval Crtx 6x software, provided by Scanco Incorporated in the manufacturer's Image Processing Language (IPL) software $(\mu \mathrm{CT}$ Evaluation Program v6; Scanco Medical AG, Brüttisellen, Switzerland) was used to assess cortical bone microstructure of the ultradistal radius and tibia. The cortical compartment in the VOI was detected automatically by identifying the endosteal and periosteal contours. All void voxels within the cortical compartment were identified, and the images were digitally superimposed, generating a refined cortical compartment region in the VOI. The Haversian canals were distinguished from artefacts because of surface roughness, transcortical foramens, or erosions. With this method, cortical porosity (CtPo; \%) and mean cortical pore diameter (CtPoDiam; $\mu \mathrm{m})$ were obtained $[22,23,25]$. The CVs for porosity were $15.9 \%$ at the radius and $5.5 \%$ at the tibia, and the CVs for mean cortical pore diameter were $6.0 \%$ at the radius and $3.9 \%$ at the tibia.

The healthy control group was assessed with the same type of XtremeCT at the Mayo Clinic in Rochester. A scan phantom for the vBMD measurements was sent from Gothenburg to Rochester for cross-calibration of the XtremeCT devices. Linear regression between the phantom measurements in Gothenburg and Rochester generated a formula

$$
((X \times 0.995)+1.148)
$$

by which the values from Rochester were subsequently adjusted. The phantom was not designed for crosscalibration of microarchitectural parameters; hence those parameters could not be compared in the patients and controls.

\section{Quantitative computed tomography}

Lumbar volumetric BMD was measured in the vertebrae L1 through L4 by using a QCT scanner (Siemens
Somatom Sensation 16 with application Syngo Osteo CT; Siemens AG, Munich, Germany). Volumetric BMD (vBMD; $\mathrm{mg} / \mathrm{cm}^{3}$ ) was assessed separately in the cortical and the trabecular bone in 10-mm-thick slices of each vertebra. All patients were scanned together with a water- and bone-equivalent calibration phantom placed below the patients along with an interpositioned gel pad to prevent artefacts and air gaps. The BMD results of the patients were compared with the reference population database of the $\mathrm{CT}$ scanner software, including 135 male and 139 female European subjects, 20 through 80 years of age.

\section{Dual-energy $\mathrm{x}$-ray absorptiometry}

BMD was measured with DXA (Hologic Discovery A; Hologic Inc., Bedford, MA, USA) in the nondominant forearm (total radius, radius 1/3) and hip (total hip, femoral neck) and in the lumbar spine (in AP L1 through L4 and lateral L2 through L4 projection) with estimation of lumbar vBMD.

\section{Radiography}

Lateral radiographs of the spinal column were taken to study the presence of vertebral fractures in the thoracic and lumbar spine by using the Genant score, which scores vertebrae on visual inspection as normal, mildly, moderately, or severely deformed (grades 0 to 3) [27]. All vertebral fractures (Genant score, 1 through 3) were included in the calculations. The presence of chronic AS changes in the cervical and lumbar spine was assessed by using the modified Stoke Ankylosing Spondylitis Spine Score (mSASSS) [28]. The score grades the anterior vertebral corners with 0 through 3 points each ( 0 , normal; 1 , erosion, sclerosis, or squaring; 2 , syndesmophyte; or 3 , bridging syndesmophyte). The scoring scale ranges from 0 to 72 .

\section{Statistical analysis}

Statistical analyses were performed by using PASW Statistics 18.0 (SPSS Inc., IBM, Chicago, IL, USA). Descriptive statistics are presented as median and range and/or mean and standard deviation (SD). The Mann-Whitney $U$ test, $t$ test, or the $X^{2}$ test was used to compare variables as appropriate. Correlations were calculated by using the Spearman correlation $\left(\mathrm{r}_{\mathrm{s}}\right)$. Logistic regressions with a forward conditional method were run with the presence of a syndesmophyte (yes/no) and vertebral fracture (yes/no) as the binary outcome. All tests were two-tailed, and $P<0.05$ was considered statistically significant.

\section{Results \\ Patients}

In total, 69 male AS patients were included in the study. The characteristics of the patients are presented in Table 1. 
Table 1 Characteristics of 69 male patients with ankylosing spondylitis in western Sweden

\begin{tabular}{|c|c|c|c|}
\hline & $n(\%)$ & Median (range) & Mean \pm SD \\
\hline Age, years & & $48(17,78)$ & $49 \pm 15$ \\
\hline Years since symptom onset & & $20(2,55)$ & $23 \pm 14$ \\
\hline Present or past iritis & $37(54)$ & & \\
\hline Present or past synovitis & $37(54)$ & & \\
\hline Patients with a vertebral fracture & $8(12)$ & & \\
\hline mSASSS & & $8(0,72)$ & $19 \pm 21$ \\
\hline BASMI, score & & $3.0(1.0,7.2)$ & $3.2 \pm 1.6$ \\
\hline BASDAl, score & & $2.7(0.2,7.9)$ & $3.1 \pm 2.0$ \\
\hline ASDAS, score & & $2.1(1.0,4.4)$ & $2.3 \pm 0.9$ \\
\hline BAS-G & & $2.2(0,9.8)$ & $3.0 \pm 2.7$ \\
\hline BASFI, score & & $2.0(0,8.7)$ & $2.6 \pm 2.2$ \\
\hline $\mathrm{ESR}, \mathrm{mm} / \mathrm{h}$ & & $10(2,73)$ & $14 \pm 12$ \\
\hline $\mathrm{CRP}, \mathrm{mg} / \mathrm{L}$ & & $5(3,71)$ & $9 \pm 12$ \\
\hline HLA-B27 positive & $65(94)$ & & \\
\hline Patients taking NSAID & $52(75)$ & & \\
\hline Patients taking glucocorticoid & $1(1)$ & & \\
\hline Patients taking DMARD & $21(30)$ & & \\
\hline Methotrexate & $13(19)$ & & \\
\hline Sulfasalazine & $5(7)$ & & \\
\hline TNF inhibitors & $15(22)$ & & \\
\hline
\end{tabular}

BASDAl, Bath Ankylosing Spondylitis Disease Activity Index; BASFI, BAS Functional Index; BASG1, BAS Patient Global score; BASMI, BAS Metrology Index; ESR, erythrocyte sedimentation rate; CRP, C-reactive protein; NSAID, nonsteroidal antiinflammatory drug; DMARD, disease-modifying antirheumatic drug; TNF, tumor necrosis factor; mSASSS, modified Stoke Ankylosing Spondylitis Spine Score.

VBMD measured with HRPQCT in the AS patients compared with the healthy controls

The AS patients had, in comparison with the controls, significantly lower vBMD in cortical bone of the ultradistal radius $(P=0.007)$ and in trabecular bone of the ultradistal tibia $(P=0.033)$ (Table 2). The AS patients also had lower weight and body mass index (BMI) than the controls, but the differences did not reach a level of significance. Weight and BMI were, however, not correlated with trabecular or cortical vBMD in the ultradistal radius or tibia. (Correlation coefficients ranged from -0.082 to 0.100 , and $P$ values ranged from 0.245 to 0.853 ).

\section{Correlation between spinal vBMD measured with QCT and peripheral bone microarchitecture measured with HRpQCT}

Strong correlations were found between trabecular vBMD in the lumbar spine, ultradistal radius $\left(\mathrm{r}_{\mathrm{S}}=0.762\right.$; $P<0.001)$ and tibia $\left(\mathrm{r}_{\mathrm{S}}=0.712 ; P<0.001\right)$, but the cortical $v B M D$ of the spine and peripheral skeleton were not significantly correlated (Figure 1 and Table 3 ). Lowlumbar trabecular vBMD was also significantly correlated
Table 2 Comparison of the demographics and HRpQCT parameters in the AS patients and healthy age-matched controls

\begin{tabular}{llccc}
\hline & & $\begin{array}{c}\text { AS } \\
\text { patients }\end{array}$ & $\begin{array}{c}\text { Healthy } \\
\text { controls }\end{array}$ & $\begin{array}{c}\text { Significance } \\
\boldsymbol{P} \text { value }\end{array}$ \\
\hline Demographics & Male \% & 100 & 100 & \\
& Age (years) & $49 \pm 14$ & $49 \pm 14$ & 0.993 \\
& BMl kg/m & $26.6 \pm 4.4$ & $27.8 \pm 4.6$ & 0.117 \\
& Height $\mathrm{cm}$ & $177 \pm 7$ & $179 \pm 7$ & 0.358 \\
& Weight $\mathrm{kg}$ & $84 \pm 14$ & $89 \pm 16$ & 0.052 \\
HRpQCT radius & DTrab $\mathrm{mg} / \mathrm{cm}^{3}$ & $181 \pm 39$ & $187 \pm 39$ & 0.460 \\
& DCort $\mathrm{mg} / \mathrm{cm}^{3}$ & $850 \pm 55$ & $874 \pm 42$ & 0.007 \\
HRpQCT tibia & DTrab $\mathrm{mg} / \mathrm{cm}^{3}$ & $187 \pm 35$ & $201 \pm 41$ & 0.033 \\
& DCort $\mathrm{mg} / \mathrm{cm}^{3}$ & $844 \pm 53$ & $845 \pm 44$ & 0.944 \\
\hline
\end{tabular}

The youngest AS patient was excluded from this analysis because of lack of a healthy control. Calculations on the tibia were made on 68 patients and controls and on radius of 61 patients and controls. The HRPQCT measurements of the radius from seven AS patients had to be excluded towing to motion artefacts. BMI, body mass index; DCort, vBMD of cortical peripheral bone; DTrab, vBMD of trabecular peripheral bone; $\mathrm{HRpQCT}$, high-resolution peripheral quantitative computed tomography.

with parameters indicating poor bone microarchitecture, such as thinner trabeculae, lower trabecular number, thinner cortex, lower cortical vBMD, and increased cortical porosity (Figure 2 and Table 3). The results thus indicated a link between trabecular bone loss in the axial and peripheral skeleton in AS.

Trabecular and cortical vBMD were significantly correlated in the ultradistal radius $\left(\mathrm{r}_{\mathrm{S}}=0.466 ; P<0.001\right)$ and tibia $\left(\mathrm{r}_{\mathrm{S}}=0.308 ; P<0.010\right)$, but the correlation did not reach the level of significance $\left(r_{S}=0.230 ; P=0.061\right)$ in the lumbar spine.

\section{Vertebral fractures in relation to bone mineral density} and peripheral bone microarchitecture

Vertebral fractures were diagnosed in eight (12\%) patients, the youngest patient being 31, and the oldest, 71 years old. Twelve vertebral fractures with Genant score grade 1 and two with grade 2 were diagnosed in the study group. Age, disease duration, and mSASSS score were not significantly different between patients with or without a vertebral fracture.

Each patient with a vertebral fracture was compared with two age-matched AS controls from the same cohort (Table 4). The patients with a vertebral fracture had significantly lower cortical lumbar vBMD measured with QCT compared with the age-matched nonfractured patients. The following DXA parameters were also significantly lower in the patients with a vertebral fracture: AP and lateral lumbar BMD, lumbar vBMD, and BMD of the hip (femoral neck and total hip).

No significant difference in BMD was found in the forearm measured by DXA between the groups. When 


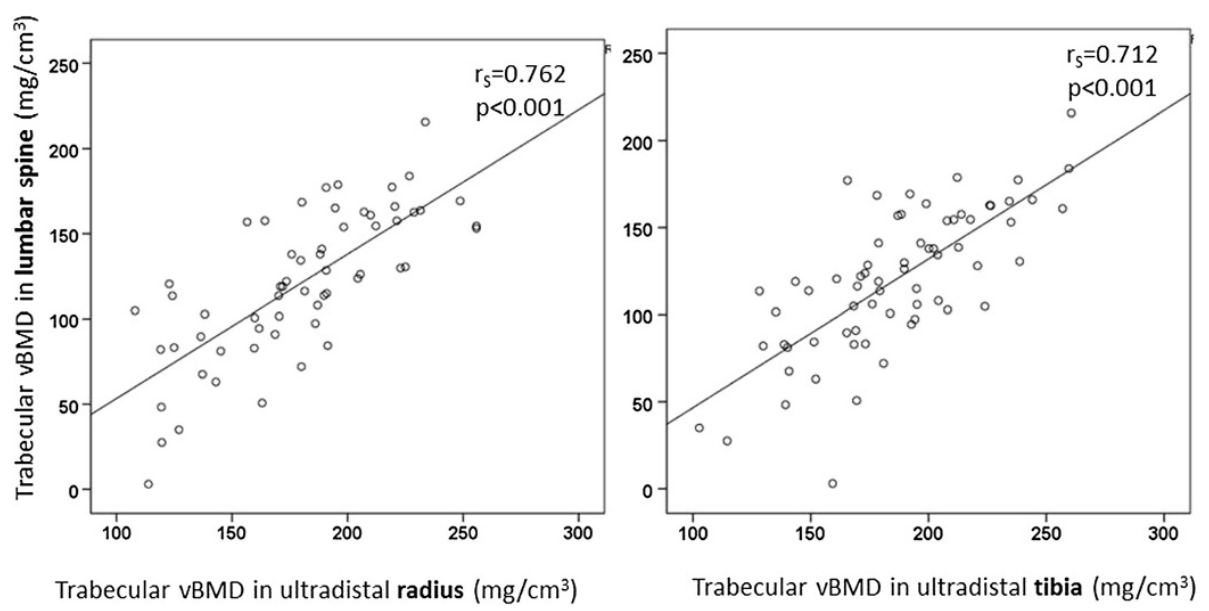

Figure 1 The correlations between trabecular volumetric BMD in the lumbar spine, ultradistal radius, and tibia.

measured with $\mathrm{HRpQCT}$, the patients with a vertebral fracture, however, displayed significantly lower trabecular and cortical vBMD in the ultradistal radius and, in addition, lower trabecular thickness, cortical thickness, and cross-sectional area in both the ultradistal radius and tibia, thus indicating deteriorated peripheral bone microarchitecture in the fractured patients in comparison with the age-matched AS controls. The greatest differences between the fractured and nonfractured patients were found in cortical thickness and cortical cross-sectional area (Table 4).

Multiple logistic regression was run with vertebral fracture as binary outcome. In the first model, in which age, mSASSS, and trabecular and cortical lumbar vBMD were entered as covariates, decreasing cortical lumbar vBMD (B $=-0.023 ; P=0.015$; OR, 0.977; 95\% CI, 0.959 to 0.996$)$, and increasing mSASSS $(\mathrm{B}=0.042 ; P=0.049$; OR, 1.04; $95 \% \mathrm{CI}, 1.0003$ to 1.087 ) were independently associated with the presence of a vertebral fracture.

In the second model, in which the HRpQCT parameters were directly measured and not derived (DTrab, DCort, TbN, CortCSA, and CortPm) were additionally entered, only decreasing cortical cross-sectional area of the tibia $(\mathrm{B}=-0.063 ; P=0.008$; OR, $0.939 ; 95 \% \mathrm{CI}, 0.897$ to 0.984 ) remained significantly associated with the presence of a vertebral fracture.

\section{Syndesmophyte formation in relation to spinal VBMD measured with QCT and peripheral bone microarchitecture}

Increasing mSASSS correlated significantly with increasing age $\left(r_{S}=0.546 ; P<0.001\right)$ and decreasing trabecular vBMD in the lumbar spine $\left(\mathrm{r}_{S}=-0.620 ; P<0.001\right)$. In addition, mSASSS correlated with increasing cortical porosity and decreasing trabecular thickness and vBMD of trabecular and cortical bone in the periphery (Table 3).
In 39 patients, radiographs of the cervical and lumbar spines revealed at least one syndesmophyte or bridging syndesmophyte, whereas nine patients had a disease restricted to the sacroiliac joints $(\mathrm{mSASSS}=0)$, and 21 patients had only the presence of erosions, sclerosis, or squaring at the vertebral corners.

The patients with at least one syndesmophyte had, in comparison with patients without syndesmophytes, significantly older age $(54 \pm 12$ versus $42 \pm 15$ years; $P=0.001$ ), thinner trabeculae in the ultradistal radius $(0.071 \pm 0.016$ versus $0.085 \pm 0.014, P<0.001)$ and tibia $(0.072 \pm 0.013$ versus $0.081 \pm 0.008 ; P=0.001)$ and lower trabecular vBMD in the lumbar spine $(100 \pm 36$ versus $146 \pm 33 ; P<0.001)$, ultradistal radius $(171 \pm 42$ versus $196 \pm 29 ; P=0.013)$ and tibia $(175 \pm 37$ versus $205 \pm 27$; $P<0.001$ ).

In a multiple logistic regression model with the presence of at least one syndesmophyte as the binary outcome and adjusting for age, decreasing lumbar trabecular vBMD ( $\mathrm{B}=-0.058 ; P<0.001 ; \mathrm{OR}=0.943 ; 95 \% \mathrm{CI}, 0.917$ to 0.970$)$, but increasing lumbar cortical vBMD $(B=0.019 ; P=$ 0.016; OR, 1.019; $95 \%$ CI, 1.004 to 1.035 ) remained independently associated with syndesmophyte formation. None of the HRpQCT parameters was significantly associated with presence of syndesmophytes after adjusting for age in logistic regression. Covariates in the regression model were age, trabecular and cortical lumbar vBMD, and the HRpQCT parameters, which were directly measured and not derived (DTrab, DCort, TbN, CortCSA, and CortPm).

\section{Comparisons of BMD measured with QCT and with DXA} in AP and lateral projections in the lumbar spine QCT revealed significantly more cases with $\mathrm{T}$ score $\leq 2.5$ SD $(n=26 ; 38 \%)$ and T score $\leq 1.0 \mathrm{SD}(n=21 ; 30 \%)$ than AP DXA, showing considerably less osteoporosis $(n=4$; 
Table 3 The correlation (Spearman rho) between the HRpQCT parameters, age, lumbar QCT, and mSASSS in the AS patients

\begin{tabular}{|c|c|c|c|c|c|c|c|c|c|}
\hline HRpQCT radius & DTrab $\left(\mathrm{mg} / \mathrm{cm}^{3}\right)$ & BV/TV (\%) & Tbth $(\mu \mathrm{m})$ & TbN (per mm) & TbSp ( $\mu \mathrm{m})$ & DCort $\left(\mathrm{mg} / \mathrm{cm}^{3}\right)$ & CortTh $(\mu \mathrm{m})$ & CtPo (\%) & CtPoDiam $(\mu \mathrm{m})$ \\
\hline \multirow[t]{2}{*}{ Age } & -0.471 & -0.473 & -0.507 & -0.040 & 0.166 & -0.337 & -0.228 & 0.540 & 0.055 \\
\hline & $P<0.001$ & $P<0.001$ & $P<0.001$ & $P=0.755$ & $P=0.198$ & $P=0.007$ & $P=0.075$ & $P<0.001$ & $P=0.663$ \\
\hline Lumb QCT & 0.762 & 0.763 & 0.737 & 0.106 & -0.304 & 0.425 & 0.420 & -0.480 & -0.136 \\
\hline Trab vBMD & $P<0.001$ & $P<0.001$ & $P<0.001$ & $P=421$ & $P=0.018$ & $P=0.001$ & $P=0.001$ & $P<0.001$ & $P=0.290$ \\
\hline Lumb QCT & 0.296 & 0.298 & 0.152 & 0.296 & -0.341 & 0.123 & 0.152 & 0.032 & 0.006 \\
\hline Cort vBMD & $P=0.021$ & $P=0.021$ & $P=0.246$ & $P=0.022$ & $P=0.008$ & $P=0.348$ & $P=247$ & $P=0.805$ & $P=0.961$ \\
\hline \multirow[t]{2}{*}{ Msasss } & -0.400 & -0.400 & -0.528 & 0.077 & 0.039 & -0.192 & -0.196 & 0.352 & 0.022 \\
\hline & $P=0.001$ & $P=0.001$ & $P<0.001$ & $P=0.552$ & $P=0.761$ & $P=0.135$ & $P=0.128$ & $P=0.004$ & $P=0.861$ \\
\hline \multirow[t]{2}{*}{ HRpQCT tibia } & DTrab & $\mathrm{BV} / \mathrm{TV}$ & Tbth & $\mathrm{TbN}$ & TbSp & DCort & CortTh & CtPo & CtPoDiam \\
\hline & $\left(\mathrm{mg} / \mathrm{cm}^{3}\right)$ & (\%) & $(\mu \mathrm{m})$ & $\left(\mathrm{mm}^{-1}\right)$ & $(\mu \mathrm{m})$ & $\left(\mathrm{mg} / \mathrm{cm}^{3}\right)$ & $(\mu \mathrm{m})$ & (\%) & $(\mu \mathrm{m})$ \\
\hline \multirow[t]{2}{*}{ Age } & -0.470 & -0.471 & -0.479 & -0.185 & 0.246 & -0.436 & -0.202 & 0.521 & 0.210 \\
\hline & $P<0.001$ & $P<0.001$ & $P<0.001$ & $P=0.127$ & $P=0.042$ & $P<0.001$ & $P=0.096$ & $P<0.001$ & 0.084 \\
\hline Lumb QCT & 0.712 & 0.714 & 0.523 & 0.363 & -0.443 & 0.454 & 0.403 & -0.496 & -0.437 \\
\hline Trab vBMD & $P<0.001$ & $P<0.001$ & $P<0.001$ & $P=0.003$ & $P<0.001$ & $P<0.001$ & $P=0.001$ & $P<0.001$ & $P<0.001$ \\
\hline Lumb QCT & 0.336 & 0.336 & 0.027 & 0.356 & -0.367 & 0.135 & 0.151 & -0.102 & -0.162 \\
\hline Cort vBMD & $P=0.005$ & $P=0.005$ & $P=0.827$ & $P=0.003$ & $P=0.002$ & $P=0.276$ & $P=0.223$ & $P=0.410$ & $P=0.191$ \\
\hline \multirow[t]{2}{*}{ mSASSS } & -0.475 & -0.475 & -0.488 & -0.105 & 0.176 & -0.315 & -0.161 & 0.363 & 0.169 \\
\hline & $P<0.001$ & $P<0.001$ & $P<0.001$ & $P=0.392$ & $P=0.148$ & $P=0.008$ & $P=0.186$ & $P=0.002$ & $P=0.169$ \\
\hline
\end{tabular}

$\overline{\mathrm{BV} / \mathrm{TV}}$, trabecular bone volume fraction; Cort, cortical; DCort, vBMD of cortical peripheral bone; DTrab, vBMD of trabecular peripheral bone; CortTh, cortical thickness peripheral bone; CtPo, cortical porosity; CtPoDiam, mean cortical pore diameter; HRpQCT, high-resolution peripheral quantitative computed tomography; Lumb, lumbar; TbN, trabecular number peripheral bone; TbSp, trabecular separation peripheral bone; Tbth, trabecular thickness peripheral bone; Trab, trabecular; $\mathrm{VBMD}$, volumetric bone mineral density; QCT, quantitative computed tomography. 


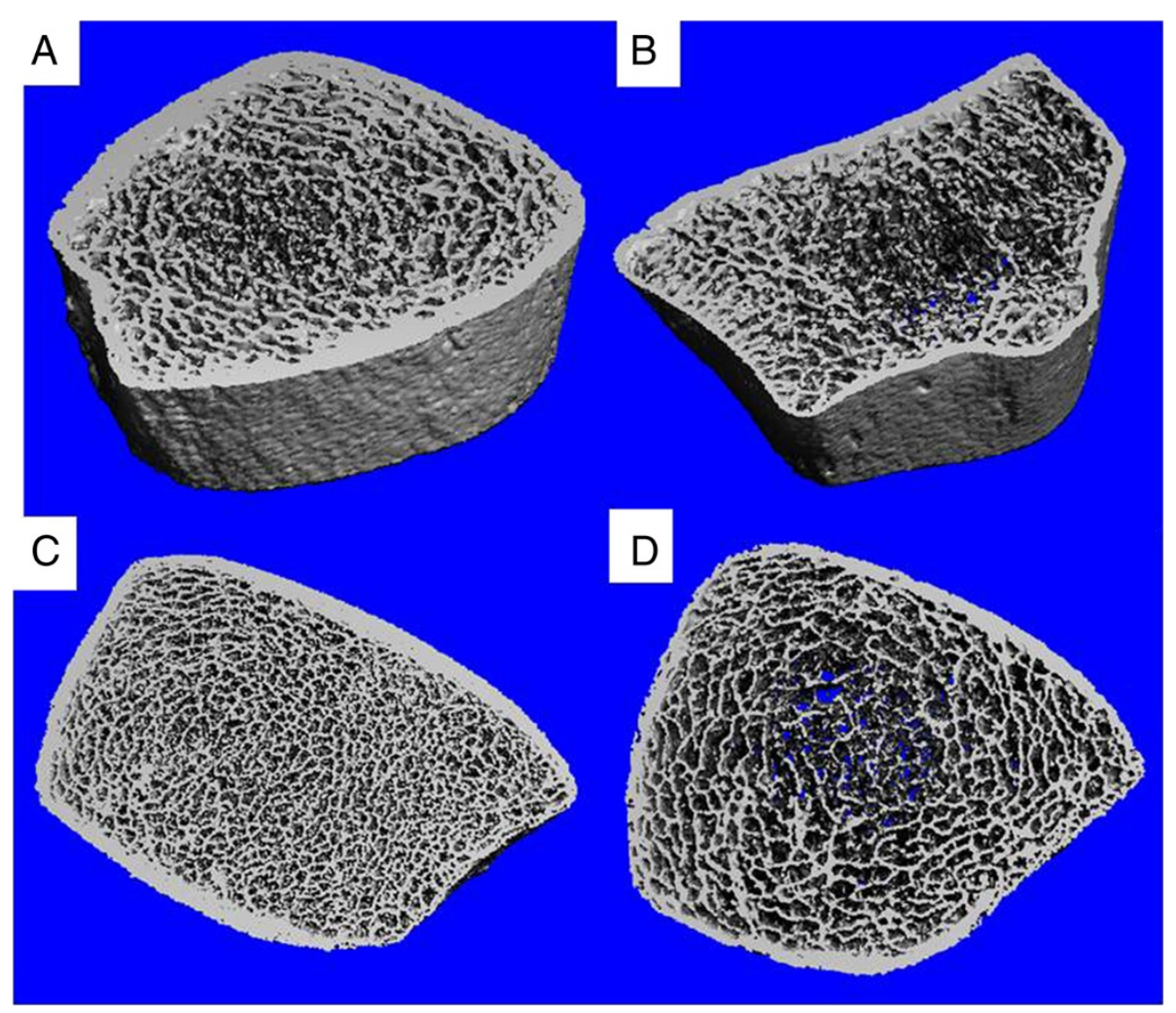

Figure 2 HRpQCT images of ultradistal radius and tibia. (A) 3D representation of ultradistal tibia. AS patient with normal BMD. (B) 3D representation of ultradistal radius. AS patient with osteoporosis. (C) 2D representation of ultradistal tibia. AS patient with normal BMD. (D) 2D representation of ultradistal tibia. AS patients with lumbar osteoporosis. Note the low trabecular number and thickness, high trabecular separation, and low cortical thickness.

$6 \%)$ and osteopenia $(n=13 ; 19 \% ; P<0.001)$. No reference database values were available for lateral lumbar DXA and DXA vBMD lumbar spine.

The patients with at least one syndesmophyte had significantly reduced $\mathrm{Z}$ scores of lumbar vBMD measured with QCT (mean Z score, $-0.624 \pm 1.186 ; P=0.003$ ), whereas AP lumbar DXA showed no significant reduction of the $\mathrm{Z}$ scores of lumbar BMD in patients with or without syndesmophytes, thus indicating that the QCT results were less affected by syndesmophyte formation than was the AP lumbar DXA.

Correlation analyses between lumbar QCT and lumbar DXA demonstrated that QCT trabecular vBMD had the strongest correlation with DXA vBMD $\left(r_{S}=0.636\right.$; $P<0.001)$ followed by lateral BMD $\left(\mathrm{r}_{\mathrm{S}}=0.537 ; P<0.001\right)$ and AP BMD $\left(\mathrm{r}_{\mathrm{S}}=0.380 ; P=0.002\right)$. QCT cortical vBMD correlated with DXA in the following way: lateral BMD $\left(\mathrm{r}_{\mathrm{S}}=0.595 ; P<0.001\right), \mathrm{AP}$ BMD $\left(\mathrm{r}_{\mathrm{S}}=0.541 ; P=0.002\right)$ and $v B M D\left(r_{S}=0.431 ; P<0.001\right)$.

\section{Discussion}

In the present study, we used new imaging techniques, peripheral HRpQCT and lumbar QCT, to investigate the relation between osteoporosis, osteoproliferation, and fractures in the spine and morphology and bone density in the peripheral skeleton.

When measured with HRpQCT, the patients with AS had lower $\mathrm{vBMD}$ in the peripheral skeleton than did healthy controls; the AS patients had significantly lower vBMD in the cortical bone of the radius and the trabecular bone of the tibia. The controls were slightly heavier than the AS patients, but it seems unlikely that this would explain the difference, because vBMD in ultradistal radius and tibia were not correlated with weight or BMI.

The HRpQCT measurements of the radius from seven patients had to be excluded for motion artefacts. Absolute immobilization of the limb is required during the procedure, but in a few patients, an optimal positioning was difficult to obtain, because of stiffness of the spine or joints.

It was previously argued that osteoporosis in AS affects mainly the axial skeleton $[12,29,30]$. The current study indicates, nevertheless, that axial and peripheral trabecular bone loss are connected in AS. Spinal and peripheral trabecular vBMD were strongly correlated. Decreasing lumbar vBMD measured with QCT was, in addition, associated with deteriorated peripheral bone microarchitecture, such as thinner trabeculae, higher trabecular 
Table 4 BMD and microarchitectural parameters in AS patients with a vertebral fracture compared with age-matched AS patients without a vertebral fracture

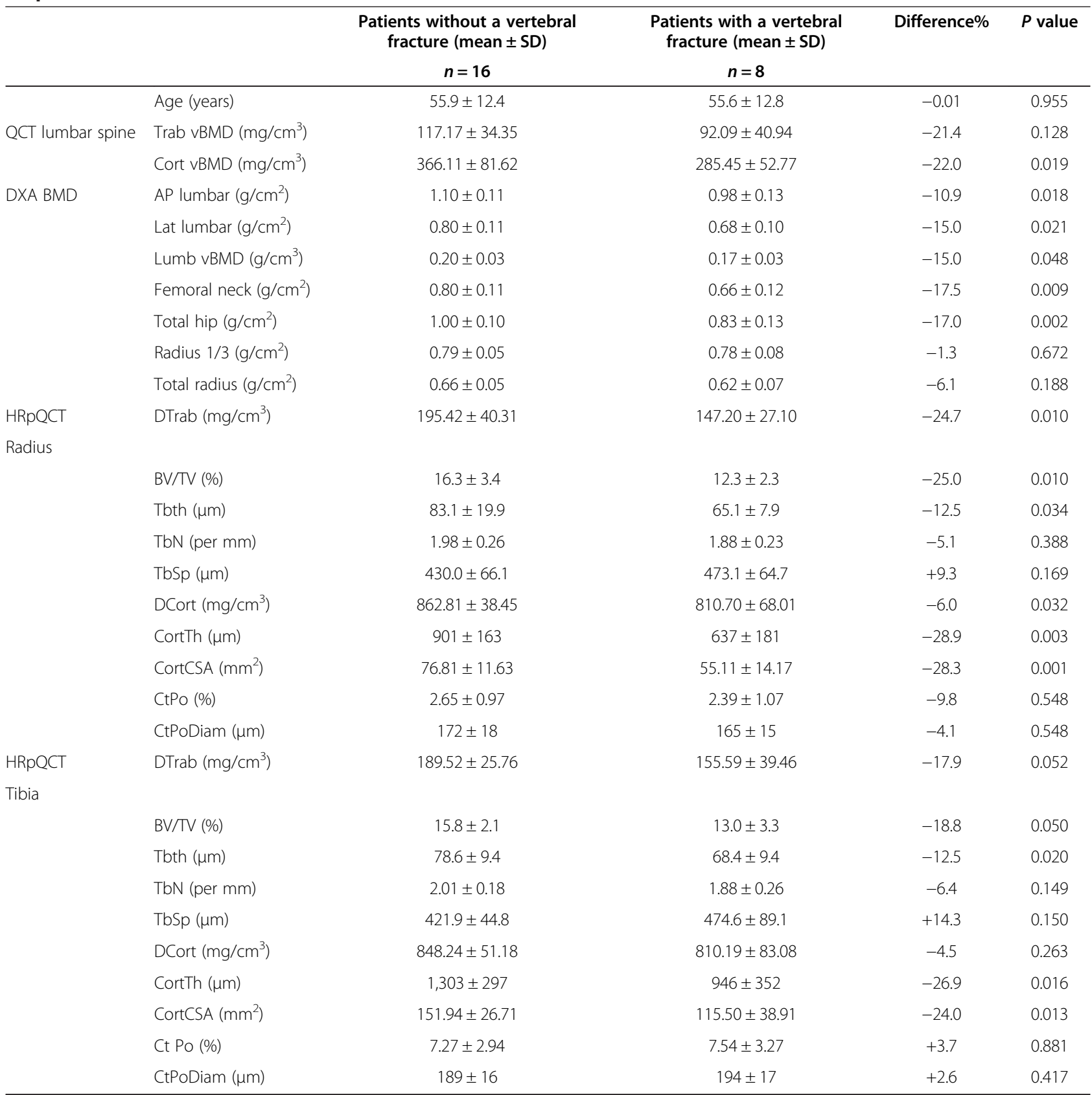

Difference (\%), mean of fractured - mean of nonfractured/mean of nonfractured; BMD, bone mineral density; BV/TV, trabecular bone volume fraction; Cort, cortical; DCort, vBMD of cortical peripheral bone; DTrab, vBMD of trabecular peripheral bone; DXA, dual-energy x-ray absorptiometry; CortCSA, cortical cross-sectional area peripheral bone; CortTh,cortical thickness peripheral bone, $\mathrm{CtPo}=$ cortical porosity; CtPoDiam, mean cortical pore diameter; HRpQCT, high-resolution peripheral quantitative computed tomography; TbN, trabecular number peripheral bone; TbSp, trabecular separation peripheral bone; Tbth, trabecular thickness peripheral bone; Trab, trabecular; $\mathrm{VBMD}$, volumetric $\mathrm{BMD} ; \mathrm{QCT}$, quantitative computed tomography.

separation, and reduced cortical thickness. This may explain the increased frequency of hip and peripheral fractures observed in an earlier study on Swedish AS patients [5].

A plausible reason for the coupling of trabecular bone loss in the axial and peripheral skeleton is that general inflammation in AS with systemic elevation of cytokines, such as TNF- $\alpha$, IL-1, and IL-6, affects osteoclasts and osteoblasts in all bone tissue. Trabecular bone loss in the vertebral bodies may, in addition, be enhanced by local inflammation and alterations of loading due to syndesmophytes and ankylosis.

In 1997, a study on 14 men with AS showed that cancellous bone volume from iliac crest biopsies correlated 
well with lumbar spine BMD measured with QCT, but not with DXA. The trabecular thickness in the biopsies of the AS patients was found to be lower than the reference values reported in the literature [31]. In contrast, another study reported no correlation between vBMD measured in the forearm with peripheral QCT (pQCT) and QCT values of the lumbar spine, and $\mathrm{pQCT}$ revealed only a few cases of osteopenia and osteoporosis. However, the patients were younger than in the present study (mean, 40 versus 49 years), and both sexes were included [7]. HRpQCT and pQCT assess different aspects of bone quality, which may also explain the discrepancy between the studies; HRpQCT measures predominantly trabecular bone in greater detail and in a more distal part of the radius and tibia, whereas $\mathrm{PQCT}$ gives a better evaluation of cortical bone.

Trabecular number was not associated with lumbar vBMD or age in the present study. Similarly, studies on age-related changes in the general population have shown decreased trabecular thickness, but preserved trabecular number in men, in contrast to loss of trabecular number and increased trabecular separation in women [32,33].

The current study also shows that AS patients with vertebral fractures have worse bone microarchitecture and lower vBMD in both the axial and peripheral skeleton than do age-matched AS controls. In this aspect, the situation in AS seems comparable to that in postmenopausal women and men aged older than 50 years, where vertebral fractures also have been shown to be associated with poor peripheral bone microarchitecture [34-36]. We identified cortical thinning and low cross-sectional area in the peripheral skeleton as factors strongly associated with vertebral fractures. Interestingly, another study on 920 men from the general population aged older than 50 also indicated that low cortical thickness and low cortical density in both the ultradistal radius and tibia were associated with vertebral fractures [34].

We found that the presence of syndesmophytes was associated with lower trabecular vBMD but increasing cortical vBMD in the lumbar spine. The increasing cortical $\mathrm{vBMD}$ was presumably reflecting pathologic newbone formation in the cortex of the vertebral bodies. Our findings are supported by an earlier study also reporting decreasing trabecular but increasing cortical vBMD in the lumbar spine measured with QCT in AS patients in advancing stages of ankylosis [37]. The pathologic new-bone formation in the spine was, however, not coupled with any signs of hyperostosis in the peripheral microarchitecture. In contrast, it was associated with lower peripheral trabecular density and thinner trabeculae. The findings support the concept of osteoproliferation as being a local anabolic bone response to inflammation, mechanical stress, or microdamage, but not a systemic process in AS.
In the present study, lateral lumbar BMD and estimated vBMD by DXA correlated well with QCT measures of both cortical and trabecular BMD. QCT was more sensitive than AP DXA in revealing reduced BMD in the lumbar spine. We recently published data showing that lateral DXA scanning with estimation of vBMD in comparison with AP DXA is more sensitive in detecting reduced BMD, less affected by the pathologic new-bone formation in the spine, and better associated with vertebral fractures [13]. QCT has hitherto been considered to be the preferred method for measuring lumbar BMD in AS, but radiation doses and availability are, however, problems of QCT. We propose that lateral lumbar DXA with estimation of vBMD may be a valuable alternative for the assessment of lumbar BMD in AS.

The lack of a Swedish control group for the HRpQCT measurements is a limitation of the study. The healthy controls were, however, matched for age, height, weight, and BMI, and Olmsted county in Minnesota has a high proportion of inhabitants of Scandinavian descent. Other limitations are the relatively small reference population for lumbar QCT and the absence of a reference-population database for men regarding lateral lumbar DXA.

\section{Conclusions}

The HRpQCT measurements revealed lower vBMD in the ultradistal radius and tibia in the AS patients compared with the healthy controls. Low-lumbar vBMD, vertebral fractures, and chronic AS-related changes in the spine were associated with lower vBMD and worse bone microarchitecture in the peripheral skeleton. The results indicate that osteoporosis in AS is a general process affecting both the central and the peripheral skeleton, whereas pathologic new-bone formation is localized.

\section{Abbreviations}

AP: Anteroposterior; AS: Ankylosing spondylitis; ASDAS: Ankylosing spondylitis disease activity acore; BASDAl: Bath ankylosing spondylitis disease activity score; BASFI: Bath ankylosing spondylitis functional index; BAS-G: Bath ankylosing spondylitis patient global score; BASMI: Bath ankylosing spondylitis metrology index; BMD: Bone mineral density; BMI: Body mass index; BV/TV: Trabecular bone volume fraction; Cort: Cortical; CortCSA: Cortical cross-sectional area peripheral bone; CortPm: Cortical periosteal circumference peripheral bone; CortTh: Cortical thickness peripheral bone; CRP: C-reactive protein; CtPo: Cortical porosity; CtPoDiam: Mean cortical pore diameter; CV: Coefficient of variation; DCort: Volumetric BMD of cortical peripheral bone; DMARD: Disease-modifying antirheumatic drug; DTrab: Volumetric BMD of trabecular peripheral bone; DXA: Dual-energy x-ray absorptiometry; ESR: Erythrocyte sedimentation rate; HRpQCT: High-resolution peripheral quantitative computed tomography; mSASSS: Modified stoke ankylosing spondylitis spine score; NSAID: Nonsteroidal antiinflammatory drug; QCT: Quantitative computed tomography;

TbN: Trabecular number peripheral bone; TbSp: Trabecular separation peripheral bone; Tbth: Trabecular thickness peripheral bone; TNF: Tumor necrosis factor; Totarea: Total bone area peripheral bone; Trab: Trabecular; VBMD: Volumetric bone mineral density; VOl: Volume of interest.

\section{Competing interests}

The authors declare that they have no competing interests. 


\section{Authors' contributions}

Study design was performed by EK, HF, and $\mathrm{HC}$. EK, HF, ML, DM, JG, MG, and $\mathrm{HC}$ conducted the study. Data were collected by EK, HF, ML, DM, JG, MG, $\mathrm{CO}$, SK, and EA. Data analysis was performed by EK, HF, ML EA, and SK. Data were interpreted by EK and HF. EK drafted the manuscript, and EK revisedmanuscript content. EK, HF, ML, JG, DM, MG, CO, EA, SK, and HC. EK and $\mathrm{HF}$ take responsibility for the integrity of the data analysis. All authors read and approved the final manuscript.

\section{Acknowledgements}

We thank all the patients who participated in the study.

This study was supported by grants from The Health and Medical Care Executive Board of the Västra Götaland, Rune and Ulla Amlövs Foundation for Rheumatology Research, Göteborg's Association Against Rheumatism, The Medical Society of Göteborg, the Medical Society of Göteborg, and the Region Västra Götaland (agreement concerning research and education of doctors), COMBINE, the Margareta Rheuma research foundation, the Inger Bendix foundation, the Swedish Research Council, the Swedish Foundation for Strategic Research, European Commission, the Lundberg Foundation, the Torsten and Ragnar Söderberg's Foundation, Petrus and Augusta Hedlund's Foundation, the ALF/LUA grant from the Sahlgrenska University Hospital, the Novo Nordisk Foundation, Gustaf $\vee$ and Queen Victoria's Masonic Foundation, and NIH R01 AR027065, and UL1 TR000135 (Mayo Center for Translational Science Activities).

\section{Author details}

'Department of Rheumatology and Inflammation Research, Sahlgrenska Academy at the University of Gothenburg, Gothenburg, Sweden. ${ }^{2}$ Centre for Bone and Arthritis Research, Institute of Medicine, Sahlgrenska Academy at the University of Gothenburg, Gothenburg, Sweden. ${ }^{3}$ Department of Radiology, Sahlgrenska Hospital/Mölndal, Sahlgrenska Academy at the University Hospital/Mölndal, Gothenburg, Sweden. ${ }^{4}$ Centre for Medica Imaging and Physiology, Skåne University Hospital, Lund, Lund University, Lund, Sweden. ${ }^{5}$ College of Medicine, Mayo Clinic, Rochester, MN, USA.

${ }^{6}$ College of Physiology and Medicine, Mayo Clinic, Rochester, MN, USA.

Received: 3 July 2013 Accepted: 15 October 2013

Published: 5 November 2013

\section{References}

1. Cooper C, Carbone L, Michet CJ, Atkinson EJ, O'Fallon WM, Melton LJ 3rd: Fracture risk in patients with ankylosing spondylitis: a population based study. J Rheum 1994, 21:1877-1882.

2. Donnelly S, Doyle DV, Denton A, Rolfe I, McCloskey EV, Spector TD: Bone mineral density and vertebral compression fracture rates in ankylosing spondylitis. Ann Rheum Dis 1994, 53:117-121.

3. Mitra D, Elvins DM, Speden DJ, Collins AJ: The prevalence of vertebral fractures in mild ankylosing spondylitis and their relationship to bone mineral density. Rheumatology (Oxford) 2000, 39:85-89.

4. Vosse D, Landewe R, van der Heijde D, van der Linden S, van Staa TP, Geusens P: Ankylosing spondylitis and the risk of fracture: results from a large primary care-based nested case-control study. Ann Rheum Dis 2009, 68:1839-1842.

5. Weiss RJ, Wick MC, Ackermann PW, Montgomery SM: Increased fracture risk in patients with rheumatic disorders and other inflammatory diseases: a case-control study with 53,108 patients with fracture. J Rheum [Research Support, Non-U.S. Gov't] 2010, 37:2247-2250.

6. Robinson Y, Sanden B, Olerud C: Increased occurrence of spinal fractures related to ankylosing spondylitis: a prospective 22-year cohort study in 17,764 patients from a national registry in Sweden. Patient Saf Surg 2013, 7:2

7. Karberg K, Zochling J, Sieper J, Felsenberg D, Braun J: Bone loss is detected more frequently in patients with ankylosing spondylitis with syndesmophytes. J Rheum 2005, 32:1290-1298.

8. van der Weijden MA, van Denderen JC, Lems WF, Heymans MW, Dijkmans BA, van der Horst-Bruinsma IE: Low bone mineral density is related to male gender and decreased functional capacity in early spondylarthropathies. Clin Rheumatol 2011, 30:497-503.

9. Gratacos J, Collado A, Pons F, Osaba M, Sanmarti R, Roque M, Larrosa M, Munoz-Gomez J: Significant loss of bone mass in patients with early, active ankylosing spondylitis: a followup study. Arthritis Rheum 1999, 42:2319-2324
10. Maillefert JF, Aho LS, El Maghraoui A, Dougados M, Roux C: Changes in bone density in patients with ankylosing spondylitis: a two-year follow-up study. Osteoporos Int 2001, 12:605-609.

11. Jun JB, Joo KB, Her MY, Kim TH, Bae SC, Yoo DH, Kim SK: Femoral bone mineral density is associated with vertebral fractures in patients with ankylosing spondylitis: a cross-sectional study. J Rheum 2006, 33:1637-1641.

12. Ralston SH, Urquhart GD, Brzeski M, Sturrock RD: Prevalence of vertebral compression fractures due to osteoporosis in ankylosing spondylitis. BMJ 1990, 300:563-565.

13. Klingberg E, Lorentzon M, Mellstrom D, Geijer M, Gothlin J, Hilme E, Hedberg M, Carlsten H, Forsblad-d'Elia H: Osteoporosis in ankylosing spondylitis: prevalence, risk factors and methods of assessment. Arthritis Res Ther [Research Support, Non-U.S. Gov't] 2012, 14:R108.

14. El Maghraoui A: Osteoporosis and ankylosing spondylitis. Joint Bone Spine 2004, 71:291-295.

15. Lange U, Kluge A, Strunk J, Teichmann J, Bachmann G: Ankylosing spondylitis and bone mineral density: what is the ideal tool for measurement? Rheum Int 2005, 26:115-120.

16. Szulc P, Munoz F, Duboeuf F, Marchand F, Delmas PD: Bone mineral density predicts osteoporotic fractures in elderly men: the MINOS study. Osteoporos Int 2005, 16:1184-1192.

17. Schuit SC, van der Klift M, Weel AE, de Laet CE, Burger H, Seeman E, Hofman A, Uitterlinden AG, van Leeuwen JP, Pols HA: Fracture incidence and association with bone mineral density in elderly men and women: the Rotterdam Study. Bone 2004, 34:195-202.

18. Fields AJ, Eswaran SK, Jekir MG, Keaveny TM: Role of trabecular microarchitecture in whole-vertebral body biomechanical behavior. J Bone Miner Res 2009, 24:1523-1530.

19. Seeman E: The growth and age-related origins of bone fragility in men. Calcif Tissue Int 2004, 75:100-109.

20. Fields AJ, Nawathe S, Eswaran SK, Jekir MG, Adams MF, Papadopoulos P, Keaveny TM: Vertebral fragility and structural redundancy. J Bone Miner Res 2012, 27:2152-2158.

21. van der Linden S, Valkenburg HA, Cats A: Evaluation of diagnostic criteria for ankylosing spondylitis: a proposal for modification of the New York criteria. Arthritis Rheum 1984, 27:361-368.

22. Burghardt AJ, Kazakia GJ, Ramachandran S, Link TM, Majumdar S: Age- and gender-related differences in the geometric properties and biomechanical significance of intracortical porosity in the distal radius and tibia. J Bone Miner Res [Research Support, N.I.H., Extramural] 2010, 5:983-993.

23. Nishiyama KK, Macdonald HM, Buie HR, Hanley DA, Boyd SK: Postmenopausal women with osteopenia have higher cortical porosity and thinner cortices at the distal radius and tibia than women with normal aBMD: an in vivo HR-pQCT study. I Bone Miner Res [Comparative Study Research Support, Non-U.S. Gov't Validation Studies] 2010, 25:882-890.

24. Laib A, Hauselmann HJ, Ruegsegger P: In vivo high resolution 3D-QCT of the human forearm. Technol Health Care 1998, 6:329-337.

25. Burghardt AJ, Buie HR, Laib A, Majumdar S, Boyd SK: Reproducibility of direct quantitative measures of cortical bone microarchitecture of the distal radius and tibia by HR-pQCT. Bone [Research Support, N.I.H., Extramural Research Support, Non-U.S. Gov't] 2010, 47:519-528.

26. Bouxsein ML, Boyd SK, Christiansen BA, Guldberg RE, Jepsen KJ, Muller R: Guidelines for assessment of bone microstructure in rodents using micro-computed tomography. J Bone Miner Res [Review] 2010, 25:1468-1486

27. Genant HK, Wu CY, van Kuijk C, Nevitt MC: Vertebral fracture assessment using a semiquantitative technique. J Bone Miner Res 1993, 8:1137-1148.

28. Creemers MC, Franssen MJ, van't Hof MA, Gribnau FW, van de Putte LB, van Riel PL: Assessment of outcome in ankylosing spondylitis: an extended radiographic scoring system. Ann Rheum Dis 2005, 64:127-129.

29. Sarikaya S, Basaran A, Tekin Y, Ozdolap S, Ortancil O: Is osteoporosis generalized or localized to central skeleton in ankylosing spondylitis? J Clin Rheumatol 2007, 13:20-24.

30. Toussirot $E$, Michel F, Wendling D: Bone density, ultrasound measurements and body composition in early ankylosing spondylitis. Rheumatology (Oxford) 2001, 40:882-888.

31. Lee YS, Schlotzhauer T, Ott SM, van Vollenhoven RF, Hunter J, Shapiro J, Marcus R, McGuire JL: Skeletal status of men with early and late ankylosing spondylitis. Am J Med 1997, 103:2333-2341. 
32. Amin S, Khosla S: Sex- and age-related differences in bone microarchitecture in men relative to women assessed by high-resolution peripheral quantitative computed tomography. J Osteoporos 2012, 2012:129760.

33. Khosla S, Riggs BL, Atkinson EJ, Oberg AL, McDaniel LJ, Holets M, Peterson $J M$, Melton LJ: Effects of sex and age on bone microstructure at the ultradistal radius: a population-based noninvasive in vivo assessment J Bone Miner Res [Comparative Study Research Support, N.I.H., Extramural] 2006, 21:124-131.

34. Szulc P, Boutroy S, Vilayphiou N, Chaitou A, Delmas PD, Chapurlat R: Cross-sectional analysis of the association between fragility fractures and bone microarchitecture in older men: the STRAMBO study. J Bone Miner Res 2011, 26:1358-1367.

35. Boutroy S, Bouxsein ML, Munoz F, Delmas PD: In vivo assessment of trabecular bone microarchitecture by high-resolution peripheral quantitative computed tomography. J Clin Endocrinol Metab 2005, 90:6508-6515

36. Sornay-Rendu E, Boutroy S, Munoz F, Delmas PD: Alterations of cortical and trabecular architecture are associated with fractures in postmenopausal women, partially independent of decreased BMD measured by DXA: the OFELY study. J Bone Miner Res 2007, 22:425-433.

37. Lange U, Teichmann J, Strunk J, Muller-Ladner U, Schmidt KL: Association of 1.25 vitamin D3 deficiency, disease activity and low bone mass in ankylosing spondylitis. Osteoporos Int 2005, 16:1999-2004.

Cite this article as: Klingberg et al:: Bone microarchitecture in ankylosing spondylitis and the association with bone mineral density, fractures, and syndesmophytes. Arthritis Research \& Therapy 2013 15:R179.

\section{Submit your next manuscript to BioMed Central and take full advantage of:}

- Convenient online submission

- Thorough peer review

- No space constraints or color figure charges

- Immediate publication on acceptance

- Inclusion in PubMed, CAS, Scopus and Google Scholar

- Research which is freely available for redistribution 